\title{
INCENTIVOS LEGAIS ÀS CONSTRUÇÕES URBANAS SUSTENTÁVEIS
}

\author{
INCENTIVES TO LEGAL BUILDINGS SUSTAINABLE URBAN
}

\author{
Daniela Rocha Teixeira Riondet-Costa ${ }^{1}$ \\ Daniele Ornaghi Sant'Anna² \\ Simone Alves Alexandrino ${ }^{3}$
}

\begin{abstract}
Resumo
A partir do universo interdisciplinar que envolve os incentivos legais às construções urbanas sustentáveis e os princípios arquitetônicos que são tradicionalmente utilizados na construção civil, esta pesquisa tem por objetivo percorrer o arcabouço normativo de onze municípios brasileiros (Americana/SP, Campos do Jordão/SP, Tietê/SP, Araraquara/SP, Barretos/SP, Ipatinga/MG, Guarulhos/SP, São Vicente/SP, Goiânia/GO, Camboriú/SP e Seropédica/RJ) para identificar a maneira como esses incentivos estão sendo regulamentados e quais parâmetros de sustentabilidade estão sendo contemplados. A pesquisa possui abordagem metodológica qualitativa e quantitativa e o procedimento para coleta de dados foi a pesquisa documental. Após tais levantamentos constatou-se que alguns parâmetros de sustentabilidade estão mais presentes nos incentivos legais, tais como: iluminação natural, telhado verde, captação de água de chuva e sistema de aquecimento solar. Por fim, concluiu-se sobre a importância dos incentivos legais para que mais parâmetros de construções sustentáveis sejam inseridos em projetos arquitetônicos que atenderão às necessidades da geração atual sem comprometer a capacidade de as gerações futuras atenderem às suas próprias necessidades.
\end{abstract}

Palavras-chave: Interdisciplinar. Incentivos legais. Construções urbanas sustentáveis.

\footnotetext{
${ }^{1}$ Doutora em Ciências pelo Programa de Pós-graduação em Meio Ambiente da Universidade do Estado do Rio de Janeiro - UERJ. Professora Adjunto Nível 2 da Universidade Federal de Itajubá. Professora permanente do Programa de Pós-Graduação em Desenvolvimento, Tecnologias e Sociedade - DTecS e colaboradora do Programa de Pós-Graduação em Meio Ambiente e Recursos Hídricos - MEMARH. Pesquisadora do Núcleo de Estudos Planejamento Ambiental e Geomática - NEPA, do Grupo de Pesquisa em Desenvolvimento, Tecnologias e Sociedade, do Grupo de Estudos em Saneamento - GES e do Grupo de pesquisa em Planejamento e Gestão de Infraestrutura, pela Universidade Federal de Itajubá. Membro do Núcleo de Educação Ambiental - NEA pela UNIFEI, atuando com extensão e pesquisa. Membro do Comitê de Ética em Pesquisa - CEP/UNIFEI. E-mail: daniela.unifei@gmail.com

${ }^{2}$ Doutora em Arquitetura e Urbanismo pela Universidade de São Paulo (2015). Pesquisadora do NEPA Núcleo de Estudos Planejamento Ambiental e Geomática e do NUSUS - Núcleo de Sistemas Urbanos Sustentáveis, ambos pela Universidade Federal de Itajubá. Pesquisadora do LABSUS - Laboratório de Modelos de Sustentabilidade e das Edificações da Faculdade de Arquitetura e Urbanismo da Universidade de São Paulo. Professora adjunta da Universidade Federal de Itajubá, colaboradora da Faculdade de Arquitetura e Urbanismo da Universidade de São Paulo e da Faculdade de Tecnologia Victor Civita. E-mail: ornagui@gmail.com

${ }^{3}$ Mestre em Desenvolvimento, Tecnologias e Sociedade pela Universidade Federal de Itajubá (UNIFEI). Membro dos projetos de extensão "Pedalando UNIFEI", "Itajubá de Olho no Óleo" e "Levantamento das potencialidades da Agricultura familiar e Agroecológica das Comunidades Rurais atingidas pela Mineração nos municípios de Conceição do Mato Dentro, Alvorada de Minas e Dom Joaquim, financiado pela Cáritas MG". Voluntária como assessora jurídica junto da Organização da Sociedade Civil "Resgacti". E-mail: simonealexandrino@unifei.edu.br
} 


\section{Abstract}

From the interdisciplinary universe that involves legal incentives for sustainable urban construction and architectural principles that are traditionally used in construction, this research aims to go the normative framework of eleven municipalities (Americana/SP, Campos do Jordão/SP, Tietê/SP, Araraquara/SP, Barretos/SP, Ipatinga/MG, Guarulhos/SP, São Vicente/SP, Goiânia/GO, Camboriú/SP e Seropédica/RJ) to identify how these incentives are being regulated and what parameters sustainability are being contemplated. The research has qualitative and quantitative approach and the procedure for data collection was the documentary research. After such surveys it was found that some sustainability parameters are more present in the legal incentives, such as natural lighting, green roof, rainwater harvesting and solar heating system. Finally, it was concluded on the importance of legal incentives for more sustainable construction parameters are entered in architectural projects that meet the needs of the present generation without compromising the ability of future generations to meet their own needs.

Keywords: Interdisciplinary. Legal incentives. Sustainable urban construction. 


\section{INTRODUÇÃO}

Nos últimos anos a sustentabilidade tem sido pano de fundo de importantes debates teóricos pelo mundo. Um importante marco teórico na discussão internacional sobre o desenvolvimento sustentável aconteceu em 1972 durante a Conferência de Estocolmo. No Brasil, foi a partir da década de 1980 que a sustentabilidade passou a ser um tema considerado importante o suficiente para ser incorporado como política pública em decorrência da necessidade de se erguer a nação em bases sustentáveis.

A primeira lei brasileira a colaborar para a inserção de questões ligadas à sustentabilidade foi a Lei Federal no 6.938, de 31 de agosto de 1981, que estabelece a Política Nacional do Meio Ambiente. $\mathrm{O}$ artigo 3 o dessa lei conceitua o meio ambiente como "o conjunto de condições, leis, influências e interações de ordem física, química e biológica, que permite, abriga e rege a vida em todas as suas formas." (BRASIL, 1981). Tendo esse artigo 30 como base é possível concordar com o posicionamento de Ferreira (2000, p. 22), que subdivide o meio ambiente em elementos naturais (solo, água, ar atmosférico, flora, fauna e biosfera), elementos culturais (patrimônio artístico, histórico, turístico, paisagístico e arqueológico) e em elementos artificiais (edificações, ruas e praças). E são dos elementos artificiais, conjugado com os demais, que os centros urbanos são constituídos.

Para Jahnke, Willani e Araújo (2013) as cidades vêm se configurando em um árduo desafio aos estudiosos que buscam amenizar os problemas ambientais urbanos, tais como as enchentes, a crise hídrica, a proliferação de doenças e o recente "verão atípico" que os brasileiros enfrentaram no ano de 2014. Esses problemas se tornaram um campo interdisciplinar de discussões em busca de mecanismos capazes de resguardar o meio ambiente que é um bem essencial à qualidade de vida das pessoas.

A Constituição Federal de 1988 (CF/88) assegurou em seu artigo 225 que "todos têm direito ao meio ambiente ecologicamente equilibrado, bem de uso comum do povo e essencial à sadia qualidade de vida, impondo-se ao Poder Público e à coletividade o dever de defendê-lo e preservá-lo para as presentes e futuras gerações." (BRASIL, 1988). Para se assegurar o direito ao meio ambiente ecologicamente equilibrado, a União, os Estados, o Distrito Federal e os Municípios, dispõem de normas legais que incentivam a adoção de medidas sustentáveis nas construções urbanas. 
Dentro da realidade dos problemas ambientais urbanos pode-se dizer que a construção civil é uma das atividades responsáveis pela transformação do ambiente natural em ambiente artificial e o tamanho do ambiente construído implica em impactos ambientais, como o uso de grande quantidade de materiais de construção (os quais demandam matéria-prima natural em larga escala), substituição da cobertura vegetal pela edificada (fato que ocasiona impermeabilidade do solo), gasto de recursos naturais renováveis e não renováveis e a geração de resíduos. (VAHAN, 2011).

Sobre a forma de se organizar esse ambiente artificial nas cidades, o artigo 182 da CF/88 estipulou que "a política de desenvolvimento urbano, executada pelo Poder Público Municipal, conforme diretrizes gerais fixadas em lei, tem por objetivo ordenar o pleno desenvolvimento das funções sociais da cidade e garantir o bem-estar de seus habitantes." (BRASIL, 1988). Essas diretrizes gerais mencionadas no artigo 182 da CF/88 foram definidas pela Lei Federal no 10.257, de 10 de julho de 2001, chamada de Estatuto da Cidade.

O artigo 2ㅇ do Estatuto da Cidade dispõe que a política urbana tem por objetivo ordenar o pleno desenvolvimento das funções sociais da cidade e da propriedade urbana, mediante as seguintes diretrizes gerais:

1. Garantia do direito a cidades sustentáveis, entendido como o direito à terra urbana, à moradia, ao saneamento ambiental, à infra-estrutura urbana, ao transporte e aos serviços públicos, ao trabalho e ao lazer, para as presentes e futuras gerações; (...)

2. Cooperação entre os governos, a iniciativa privada e os demais setores da sociedade no processo de urbanização, em atendimento ao interesse social; (BRASIL, 2001).

Após a edição do Estatudo da Cidade que incentiva a ideia de cidades sustentáveis, a primeira contribuição para mudança de paradigmas na área da construção civil foi por meio da Resolução no 307, de 5 de julho de 2002, do Conselho Nacional do Meio Ambiente (CONAMA), que estabeleceu diretrizes, critérios e procedimentos para a gestão dos resíduos da construção civil, disciplinando as ações necessárias para minimizar os impactos ambientais das construções no meio urbano. (CONSELHO NACIONAL DO MEIO AMBIENTE, 2002).

Partindo desse cenário normativo que surge a importância das construções urbanas sustentáveis que têm por objetivo causar o mínimo de impacto ambiental local, aproveitar os recursos naturais renováveis, apresentar a durabilidade dos materiais construtivos e propiciar aos usuários qualidade vida.

Mas afinal, de que maneira os incentivos legais às construções urbanas sustentáveis estão sendo regulamentados e quais parâmetros de sustentabilidade estão sendo contemplados? 
A partir do universo interdisciplinar que envolve os incentivos legais às construções urbanas sustentáveis e os princípios arquitetônicos que são tradicionalmente utilizados na construção civil, esta pesquisa tem por objetivo percorrer o arcabouço normativo de onze municípios brasileiros (Americana/SP, Campos do Jordão/SP, Tietê/SP, Araraquara/SP, Barretos/SP, Ipatinga/MG, Guarulhos/SP, São Vicente/SP, Goiânia/GO, Camboriú/SP e Seropédica/RJ) para identificar a maneira como esses incentivos estão sendo regulamentados e quais parâmetros de sustentabilidade estão sendo contemplados. A pesquisa possui abordagem metodológica qualitativa e quantitativa e o procedimento para coleta de dados foi a pesquisa documental.

\section{PARÂMETROS ARQUITETÔNICOS PARA CONSTRUÇÕES SUSTENTÁVEIS}

As construções sustentáveis estão intimamente ligadas à arquitetura e aos aspectos ambientais, sendo um deles o clima. De acordo com Romero e Reis (1999) a arquitetura e o clima são conceitos inseparáveis, porém, como se produziu em larga escala uma arquitetura dissociada do clima, foi necessário a criação de uma "segunda arquitetura" batizada de bioclimática. Controvérsias subtraídas, o termo tem sido aceito no contexto acadêmico e comercial.

De acordo com Lamberts et al (2016) a arquitetura bioclimática busca utilizar, por intermédio de seus próprios elementos, as condições favoráveis para satisfazer as exigências humanas relacionadas ao conforto térmico. Segundo Brown e Dekay (2004) a arquitetura bioclimática surge em boa parte pela conscientização dos problemas relacionados à crise energética.

Alguns termos análogos à arquitetura bioclimática são comumente citados na literatura: arquitetura sustentável, bioarquitetura, ecoarquitetura e arquitetura ecológica. Outro termo comumente citado para descrever a arquitetura bioclimática é arquitetura verde. A cor verde é associada à natureza, à renovação, à esperança, ao equilíbrio e à ecologia. Também adquiriu conotação pacificadora e de proteção ao meio ambiente, sentidos abstratos impulsionados desde o movimento de contracultura que criticava o consumismo e o uso indiscriminado dos recursos naturais.

Sob a ótica da arquitetura ecológica foi introduzido o conceito de "edifícios verdes" que supostamente pretende refrear o aumento das emissões de gás carbônico $\left(\mathrm{CO}_{2}\right)$, reduzir o consumo de água e energia e evitar mudanças climáticas como uma tentativa de englobar todos os aspectos ambientais que envolvem as construções civis. (YUDELSON, 2007). 
As vantagens dos "edifícios verdes" em relação às construções convencionais segundo Yudelson (2007) são:

a. Diminuir a desigualdade da distribuição global de recursos, pois edifícios com melhor desempenho podem ser comercializados a preços menores do que os convencionais;

b. Menor perniciosidade ao meio ambiente, inclusive ao habitat urbano;

c. Gerir as águas prediais e pluviais no local;

d. Utilizar materiais sustentáveis (inclusive recicláveis) para reduzir o impacto ambiental;

e. Promover a imagem sustentável do autor, inquilino ou proprietário (green marketing);

f. Reduzir a poluição das águas de rios, oceanos e córregos em um âmbito mais urbano;

g. Estender a vida útil da infraestrutura municipal usando menos água encanada e mais águas pluviais contribuindo, assim, para o crescimento sem infraestrutura (expansão);

h. Estender a vida útil de aterros reduzindo o descarte de restos de construção.

A figura 1 representa os parâmetros de um projeto arquitetônico sustentável que de acordo com Lengen (2008) são integrar, reutilizar, reciclar dejetos e aproveitar.

\section{Figura 1 - Parâmetros de um projeto arquitetonico sustentavel}

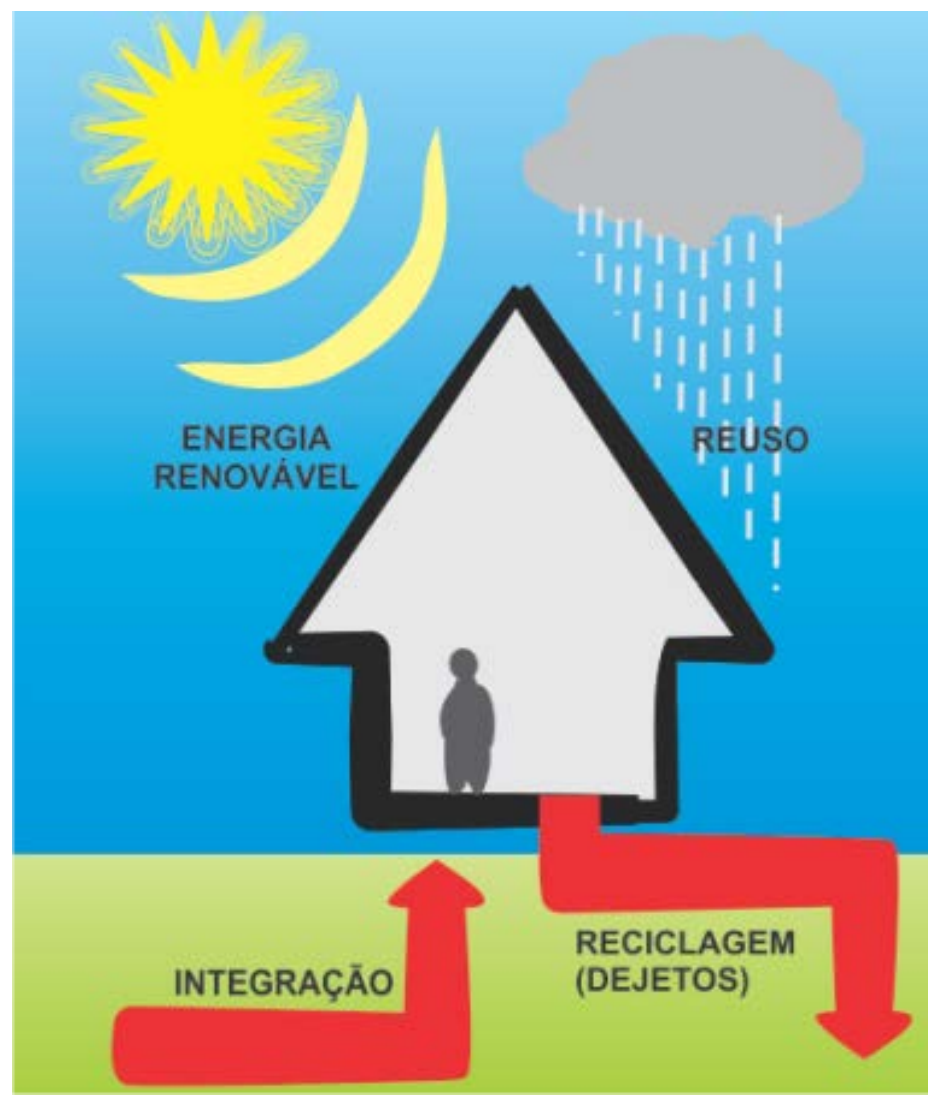

Fonte: elaborado pelas autoras 
Até o movimento de contracultura ocorrido em meados dos anos 1990 não se observava um conhecimento sistemático sobre construções sustentáveis ou os chamados "edifícios verdes" na literatura especializada em construções urbanas. Inicialmente, essa lacuna foi preenchida pelo mercado e seus sistemas de etiquetas verdes (green labeling systems), onde a simples menção à expressão edifício verde já carregava uma associação à certificação sustentável aferida por empresas privadas e organizações não-governamentais (ONGs). (SANT'ANNA, 2015).

Dentre as entidades certificadoras a ONG USGBC (U.S. Green Building Council) se destaca por mensurar e atestar a qualidade sustentável de edifícios, além de embutir o termo edifício verde na empresa (greenbuilding) - a etiquetagem é denominada LEED - Leadership in Energy \& Environmental Design. Para aferir a sustentabilidade nas edificações cada entidade certificadora de selos verdes também sugere uma classificação de parâmetros de projeto.

A entidade possui uma filial, a GBC Brasil, que propõe a seguinte classificação de sustentabilidade para as edificações:

1. Sustainable sites (Espaço Sustentável) - Encoraja estratégias que minimizam o impacto no ecossistema durante a implantação da edificação e aborda questões fundamentais de grandes centros urbanos, como redução do uso do carro e das ilhas de calor.

2. Water efficiency (Eficiência do uso da água) - Promove inovações para o uso racional da água com foco na redução do consumo de água potável e alternativas de tratamento e reuso dos recursos.

3. Energy \& atmosphere (Energia e Atmosfera) - Promove eficiência energética nas edificações por meio de estratégias simples e inovadoras, como por exemplo simulações energéticas, medições, comissionamento de sistemas e utilização de equipamentos e sistemas eficientes.

4. Materials \& resources (Materiais e Recursos) - Encoraja o uso de materiais de baixo impacto ambiental (reciclados, regionais, recicláveis, de reuso, etc.) e reduz a geração de resíduos, além de promover o descarte consciente, desviando o volume de resíduos gerados dos aterros sanitários.

5. Indoor environmental quality (Qualidade ambiental interna) - Promove a qualidade ambiental interna do ar, essencial para ambientes com alta permanência de pessoas, com foco na escolha de materiais com baixa emissão de compostos orgânicos voláteis, controlabilidade de sistemas, conforto térmico e priorização de espaços com vista externa e luz natural. 
6. Innovation in design or innovation in operations (Inovação e Processos) - Incentiva a busca de conhecimento sobre Green Buildings, assim como, a criação de medidas projetuais não descritas nas categorias do LEED. Pontos de desempenho exemplar estão habilitados para esta categoria.

7. Regional priority credits (Créditos de Prioridade Regional) - Incentiva os créditos definidos como prioridade regional para cada país, de acordo com as diferenças ambientais, sociais e econômicas existentes em cada local. Quatro pontos estão disponíveis para esta categoria. (GBCBRASIL, 2016).

Embora o sistema de critérios estabelecidos pelo LEED seja bastante interessante, não significa que uma construção não certificada pela entidade não se configure como sustentável. Os municípios brasileiros vêm, gradativamente, adotando incentivos legais que dispõe especificamente sobre a adoção de medidas de sustentabilidade nas construções urbanas. E para exemplificar essa tendência serão analisados 11 (onze) casos com o objetivo de identificar a maneira como esses incentivos estão sendo regulamentados e quais parâmetros de sustentabilidade estão sendo contemplados.

\section{APLICAÇÕES DOS INCENTIVOS LEGAIS ÀS CONSTRUÇÕES URBANAS SUSTENTÁVEIS: CASOS}

O município de Americana/SP aprovou a Lei no 4.448, de 05 de janeiro de 2007, a qual concede incentivo fiscal de redução do Imposto sobre a Propriedade Predial e Territorial Urbana (IPTU) aos imóveis urbanos edificados de uso residencial dotados de áreas verdes descobertas com solos permeáveis no pavimento térreo. Essa lei determina os seguintes percentuais de desconto:

Art. $2 \stackrel{0}{ }$. (...)

I. $10 \%$ (dez por cento) sobre o valor do Imposto Predial, quando a área abrangida pela permeabilização for superior a 15\% (quinze por cento) e inferior a 20\% (vinte por cento) da área do total do terreno;

II. $15 \%$ (quinze por cento) sobre o valor do Imposto Predial, quando a área abrangida pela permeabilização for superior a $20 \%$ (vinte por cento) e inferior a 30\% (trinta por cento) da área total do terreno;

III. $20 \%$ (vinte por cento) sobre o valor do Imposto Predial, quando a área abrangida pela permeabilização for superior a 30\% (trinta por cento) da área total do terreno.

$\S 1$ 을 as áreas verdes descobertas, com solo permeável, no pavimento térreo, previstas no caput deste artigo, deverão ter largura nunca inferior a 0,30m (trinta centímetros).

$\S 2$ ㅇ As reduções previstas nos itens I, II e III deste artigo somente serão aplicadas aos imóveis cujas edificações e construções tenham um índice de 
aproveitamento do terreno igual ou inferior a 1,5 (um e meio). (AMERICANA/SP, 2007).

A conservação de áreas verdes descobertas em imóveis urbanos edificados nos percentuais estipulados pode contribuir para a maior permeabilidade das águas pluviais, diminuindo os pontos de alagamentos na cidade, e, também, colaborar para a absorção de raios solares que quando refletidos em coberturas edificadas propiciam o aumento do aquecimento da temperatura terrestre.

No mesmo sentido, o município de Campos do Jordão/SP aprovou a Lei no 3.157, de 12 de junho 2008, onde previu o seguinte incentivo:

Art. 1‥ O terreno com área superior a $5.000 \mathrm{~m} 2$ (cinco mil metros quadrados), dotado de florestas naturais perfeitamente tratadas e conservadas, ou que seja reflorestada, ou, ainda, em que se mantenham pomares e jardins igualmente tratados e conservados, terá um desconto percentual do imposto, na seguinte proporção:

I. Até $10 \%$ (dez por cento) da área com o benefício supra, desconto de $10 \%$ (dez por cento);

II. Acima de $10 \%$ até $20 \%$ (dez - vinte por cento) de área com tais benefícios, desconto de $20 \%$ (vinte por cento);

III. Acima de $20 \%$ até $30 \%$ (vinte - trinta por cento) de área com os benefícios, desconto de 30\% (trinta por cento);

IV. Acima de $30 \%$ até $40 \%$ (trinta - quarenta por cento) de área com os benefícios, desconto de $40 \%$ (quarenta por cento);

V. Mais de $40 \%$ (quarenta por cento) da área com os benefícios, desconto de 50\% (cinqüenta por cento). (CAMPOS DO JORDÃO/SP, 2008).

Também visando à conservação de áreas verdes, o município de Tietê/SP, editou a Lei no 3.087, de 28 de agosto de 2009, que em seu Anexo I, instituiu a redução de até 100\% (cem por cento) do valor do IPTU:

\section{Quadro 1 - Áreas da Reserva Particular do Patrimônio Natural e Bosques}

\begin{tabular}{|c|c|}
\hline $\begin{array}{c}\text { Acima de 50\% (cinquenta por cento) do total de árvores } \\
\text { nativas ou exóticas, em que DC equivale ao diâmetro no colo } \\
\text { da árvore }\end{array}$ & $\begin{array}{c}\text { Percentual de desconto de IPTU } \\
\text { referente à área plantada do } \\
\text { imóvel: }\end{array}$ \\
\hline$D C<0,15 \mathrm{~m}$ & $40 \%$ (quarenta por cento) \\
\hline $0,15<\mathrm{DC}<0,45 \mathrm{~m}$ & $60 \%$ (sessenta por cento) \\
\hline $\mathrm{DC}>0,45 \mathrm{~m}$ & $100 \%$ (cem por cento) \\
\hline
\end{tabular}
Fonte: TIETÊ/SP, 2009

O município de Araraquara/SP também sancionou a Lei no 7.152, de 08 de dezembro de 2009 concedendo isenção parcial do IPTU às propriedades que conservarem área arborizada, a saber: 


\section{Quadro 2 - Os percentuais de isenção}

\begin{tabular}{|c|c|}
\hline Percentual de Área Arborizada na Propriedade & Percentual de Isenção do IPTU \\
\hline Acima de $30 \%$ até $45 \%$ & $10 \%$ (dez por cento) \\
\hline Acima de $45 \%$ até $80 \%$ & $20 \%$ (vinte por cento) \\
\hline Acima de $80 \%$ & $40 \%$ (quarenta por cento) \\
\hline
\end{tabular}

Fonte: ARARAQUARA/SP, 2009

Já o município de Barretos/SP, inovou ao aprovar a Lei Complementar no 122, de 18 de dezembro de 2009, que instituiu o programa de educação ambiental "Município Verde", incentivando outras formas de construções sustentáveis, além do envolvimento e a participação da sociedade:

Art. 2 Na adesão ao programa de educação ambiental "Município Verde" o contribuinte, inclusive o locatário de imóvel, deverá se enquadrar em uma das seguintes opções:

I. Participar da coleta seletiva de materiais recicláveis por meio do programa "Lixo que não é Lixo", em prédios residenciais, comerciais, prestadores de serviço, industriais ou de uso misto do Município;

II. Manter uma horta de no mínimo 60\% (sessenta por cento) da área total de terreno onde não haja nenhuma edificação; e

III. Construir muro e calçada na testada de terreno sem nenhuma edificação, instalar portão e plantar, no mínimo, uma árvore na calçada e deverá o terreno ser mantido limpo e roçado.

$\S 1$ - - O contribuinte que fizer adesão ao programa "Município Verde" dentro de um exercício fiscal terá garantido, no exercício subsequente, desde que comprovada a sua efetiva participação ao programa, desconto de $10 \%$ (dez por cento) na base do Imposto Predial e Territorial Urbano - IPTU, depois de computados todos e quaisquer descontos legais vigentes no exercício em curso, para pagamento à vista ou para pagamento parcelado até as datas estabelecidas.

$\S 2$ - - Na adesão ao programa "Município Verde", o contribuinte participante da coleta seletiva de materiais recicláveis, por meio do programa "Lixo que não é Lixo", mencionado no inciso I deste artigo, receberá um cartão de "Agente Cidadão" contendo o código de barras específico do seu imóvel, para lançamento, pelo "Coletor Ambiental", no ato da entrega do material reciclável, para o controle da efetiva participação do contribuinte ao programa. (BARRETOS/SP, 2009).

Percebe-se que esse município inovou ao diversificar as opções para que os cidadãos adotem ações possíveis de serem inseridas nas edificações que já estavam construídas, tais como coleta seletiva de materiais recicláveis, conservação de área verde ou a plantação de árvore na calçada. 
No Estado de Minas Gerais, o município de Ipatinga editou a Lei № 2.646, de 21 de dezembro de 2009, abrindo o leque de alternativas sustentáveis a serem incentivadas na construção civil, veja:

Art. 3 o benefício tributário, concebido na forma de desconto sobre o valor do IPTU, será concedido ao proprietário, titular do domínio útil ou possuidor, a qualquer título, de bem imóvel que neste mantiver:

I. Sistema de captação e de reuso de águas pluviais;

II. Sistema de aquecimento solar;

III. Material sustentável de construção; ou

IV. Área permeável não degradável, com cultivo de espécies arbóreas nativas.

Art. 5o O desconto no valor do IPTU será concedido na seguinte proporção:

I. $3 \%$ (três por cento) para as medidas descritas no inciso I do art. 3ㅇ desta Lei;

II. $5 \%$ (cinco por cento) para as medidas descritas nos incisos II; III e IV do art. 3o desta Lei. Parágrafo Único - Os descontos a que se referem os incisos I e II deste artigo são cumulativos para cada medida adotada, e serão somados a outros descontos eventualmente concedidos pela municipalidade, até o limite de 63\% (sessenta e três por cento) do total do imposto. (IPATINGA/MG, 2009).

Nesse município, além da preservação de solo permeável, os incentivos legais visam à diminuição do desperdício de recursos naturais como a água, a energia elétrica e a matéria prima utilizada no processo de fabricação de materiais de construção.

Em Guarulhos/SP, a Lei no 6.793, de 28 de dezembro de 2010, englobou todas as modalidades de construções urbanas sustentáveis incentivadas por lei em outros municípios brasileiros até então, dispondo da seguinte forma:

Art. 60. Será concedido desconto de até no máximo 20\% (vinte por cento) no valor do Imposto sobre a Propriedade Predial e Territorial Urbana - IPTU anual devido, pelo período de cinco exercícios consecutivos contados a partir do exercício seguinte ao da efetiva implantação ou no caso de imóveis que já tenham adotado as medidas ambientais na data da publicação da presente Lei, a partir do exercício seguinte ao da comunicação ao órgão fazendário, para os imóveis edificados que adotem duas ou mais medidas a seguir enumeradas:

I. Sistema de captação da água da chuva: $3 \%$ (três por cento) de desconto;

II. Sistema de reuso de água: $3 \%$ (três por cento) de desconto;

III. Sistema de aquecimento hidráulico solar: $3 \%$ (três por cento) de desconto;

IV. Sistema de aquecimento elétrico solar: 3\% (três por cento) de desconto;

V. Construções com material sustentável: $3 \%$ (três por cento) de desconto;

VI. Utilização de energia passiva: 3\% (três por cento) de desconto;

VII. Sistema de utilização de energia eólica: 5\% (cinco por cento) de desconto;

VIII. Instalação de telhado verde, em todos os telhados disponíveis no imóvel para esse tipo de cobertura: 3\% (três por cento) de desconto; 
IX. Separação de resíduos sólidos, benefício a ser concedido exclusivamente aos condomínios horizontais ou verticais, e que, comprovadamente, destinem sua coleta para reciclagem e aproveitamento: $5 \%$ (cinco por cento) de desconto. (GUARULHOS/SP, 2010).

Por meio da Lei Complementar no 634, de 05 de novembro de 2010, o município de São Vicente/SP, concedeu a redução da alíquota do IPTU aos proprietários de imóveis residenciais, nãoresidenciais e não-edificados que adotem medidas ambientais estimulando a proteção, preservação e a recuperação do meio ambiente. Tais medidas estão listadas no quadro 3.

\section{Quadro 3 - Anexo da Lei Complementar no 634, de 05 de novembro de 2010 (São Vicente/SP)}

\begin{tabular}{|c|c|c|}
\hline MEDIDAS ADOTADAS & MÉTODOS & REDUÇÃO \\
ALÍQUOTA
\end{tabular}




\begin{tabular}{|c|c|c|}
\hline & $\begin{array}{l}\text { responsáveis pelo aquecimento da água da } \\
\text { residência. }\end{array}$ & \\
\hline & $\begin{array}{l}\text { Sistema elétrico solar - deverá estar integrado } \\
\text { ao sistema de energia elétrica da casa e ser } \\
\text { responsável por pelo menos } 20 \% \text { do consumo } \\
\text { total da residência. }\end{array}$ & 0,13 \\
\hline & Demais técnicas ${ }^{3}$ & 0,03 \\
\hline \multirow{4}{*}{ 5. Ampliação de área permeável } & $\begin{array}{l}\text { Plantio de árvores e manutenção - defronte do } \\
\text { lote }\end{array}$ & 0,03 \\
\hline & $\begin{array}{l}\text { Áreas permeáveis "verdes" nos recuos, } \\
\text { utilizando acima de } 15 \% \text { da área do lote. }\end{array}$ & 0,07 \\
\hline & $\begin{array}{l}\text { Utilização da área em projetos ecologicamente } \\
\text { corretos, como hortas comunitárias }{ }^{5}\end{array}$ & 0,13 \\
\hline & Demais técnicas ${ }^{3}$ & 0,02 \\
\hline \multicolumn{3}{|l|}{ OBS: } \\
\hline \multicolumn{3}{|c|}{1 Medidas que deverão ser adotadas para obras novas ou reformas. } \\
\hline \multicolumn{3}{|c|}{$\begin{array}{l}2 \text { Medidas que deverão ser adotadas somente nos condomínios residenciais ou não-residenciais, } \\
\text { acima de } 6 \text { (seis) unidades e em sua totalidade. }\end{array}$} \\
\hline \multicolumn{3}{|c|}{$\begin{array}{l}3 \text { Demais técnicas que atendam às medidas de preservação ao meio ambiente não descritas neste } \\
\text { Anexo deverão ser analisadas pela COPLADI - Comissão Técnica de Acompanhamento do Plano } \\
\text { Diretor, prevista no art. } 15 \text { da Lei Complementar no 270, de } 29 \text { de dezembro de } 1999 \text {. }\end{array}$} \\
\hline \multicolumn{3}{|c|}{4 Uso obrigatório em todos os sanitários da unidade. } \\
\hline \multicolumn{3}{|l|}{5 Para terrenos baldios. } \\
\hline \multicolumn{3}{|c|}{6 Condomínios deverão apresentar políticas de redução de resíduos através de declaraç } \\
\hline
\end{tabular}

Em Goiânia/GO foram estabelecidos benefícios tributários (também em forma de desconto no IPTU) por meio da Lei Complementar no 235, de 28 de dezembro de 2012:

Art. 20 Os benefícios tributários serão concedidos em forma de descontos no Imposto Predial e Territorial Urbano/IPTU, nos seguintes percentuais e de acordo com as respectivas ações:

I. Captação e reutilização de águas pluviais ou oriundas de outras fontes $3,0 \%$ (três por cento);

II. Sistema de aquecimento hidráulico solar - 2,0\% (dois por cento);

III. Sistema de aquecimento elétrico solar - 2,0\% (dois por cento);

IV. Construção de calçadas ecológicas - 3,0\% (três por cento);

V. Arborização no calçamento - 3,0\% (três por cento);

VI. Permeabilidade do solo com cobertura vegetal - 2,0\% (dois por cento);

VII. Participação da coleta seletiva de resíduos sólidos em condomínios - 3,0\% (três por cento);

VIII. Construções com material sustentável - 3,0\% (três por cento);

IX. Instalação de telhado verde, em todos os telhados disponíveis no imóvel para esse tipo de cobertura - 3,0\% (três por cento);

X. Sistema de utilização de energia eólica - 3,0\% (três por cento). (GOIÂNIA/GO, 2012). 
Por meio da Lei no 2.544 de 03 de junho de 2013, o município de Camboriú/SC, instituiu o programa IPTU Verde, que em seu artigo 2o prevê:

Art. 2o O benefício tributário disposto consiste na redução do Imposto Predial e Territorial Urbano (IPTU) aos proprietários de imóveis residenciais e não residenciais que adotarem as seguintes medidas:

I. Sistema de captação da água da chuva;

II. Sistema de reuso de água;

III. Sistema de aquecimento hidráulico solar;

IV. Construção com materiais sustentáveis.

Art. 3o Para efeito desta Lei considere-se:

I. Sistema de captação da água da chuva: aquele que capta água da chuva e armazena em reservatório para utilização no próprio imóvel;

II. Sistema de reuso de água: aquele utilizado após o devido tratamento da água residual do próprio imóvel, para atividades que não exijam que a mesma seja potável;

III. Sistema de aquecimento hidráulico solar: aquele que utiliza sistema com a captação de energia solar térmica para aquecimento de água, com a finalidade de reduzir parcialmente o consumo de energia elétrica na residência;

IV. Construção com materiais sustentáveis: aquele que utiliza matérias que atuem os impactos ambientais, o que deve ser comprovado mediante apresentação de selo certificado.

Art. 40 O benefício tributário no Imposto Predial e Territorial Urbano (IPTU) para o caso das medidas dispostas no art. 2 o desta Lei será concedido nas seguintes proporções:

I. $2 \%$ para as medidas descritas nos incisos I e II;

II. $4 \%$ para a medida descrita no inciso III;

III. 6\% para medida descrita no inciso IV.

(CAMBORIÚ/SC, 2013).

E finalizando, o município de Seropédica/RJ, por meio da Lei no 526, de 15 de julho de

2014, estabeleceu que:

Art. 2 ㅇ Será concedido desconto no Imposto Territorial e Predial Urbano (IPTU) anual, em no máximo 15\% (quinze por cento), aos proprietários de imóveis residenciais e não residenciais, que adotarem as seguintes medidas:

I. Sistema de Captação e utilização de água pluvial: $3 \%$ (três por cento) de desconto;

II. Sistema de reuso de água residual, atender aos parâmetros da ANVISA, da ABNT, da OMS e do CONAMA: $3 \%$ (três por cento) de desconto;

III. Sistema de aquecimento solar: $3 \%$ (três por cento) de desconto;

IV. Sistema de aproveitamento energético solar: $4 \%$ (quatro por cento) de desconto;

V. Construções com material sustentável: 3\% (três por cento) de desconto, mediante comprovação documentada e sujeito à aprovação na Secretaria Municipal de Ambiente e Agronegócio - SEMAMA;

VI. Separação e encaminhamento de resíduos sólidos inorgânicos para reciclagem, com documento de comprovação da instituição receptora, registrada: $2 \%$ (dois por cento) de desconto; 
VII. Separação de resíduos agrossilvopastoris para destinação ambiental adequada, com documentação de comprovação da instituição receptora, registrada e licenciada pelo Instituto Estadual do Ambiente - INEA: 2\% (dois por cento) de desconto;

VIII. Plantio(s) de muda(s) (espécies arbóreas nativas com altura mínima de 1,5 metros) e disposição de áreas verdes de no mínimo 5\% da extensão total do imóvel, de modo a garantir a permeabilidade e a capacidade de escoamento da água no solo: $4 \%$ (quatro por cento) de desconto. (SEROPÉDICA/RJ, 2014).

Observando as normas municipais anteriormente listadas procedeu-se a um enquadramento dos incentivos concedidos pelos municípios analisados no contexto dos parâmetros da certificação denominada LEED. Os aspectos contemplados pelas municipalidades analisadas estão expressos no quadro 4.

\section{Quadro 4 - Cruzamento de parâmetros do LEED com os incentivos fiscais} municipais

\begin{tabular}{|c|c|c|c|c|c|}
\hline $\begin{array}{c}\text { Município/Parâmetro } \\
\text { LEED }\end{array}$ & $\begin{array}{c}\text { Espaço } \\
\text { sustentável }\end{array}$ & $\begin{array}{c}\text { Materiais } \\
\text { Recursos }\end{array}$ & $\begin{array}{c}\text { Energia e } \\
\text { Atmosfera }\end{array}$ & $\begin{array}{c}\text { Qualidade } \\
\text { Ambiental } \\
\text { Interna }\end{array}$ & $\begin{array}{c}\text { Uso } \\
\text { Racional da } \\
\text { Água }\end{array}$ \\
\hline Americana/SP & $\bullet$ & & & & \\
\hline Campos do Jordão/SP & $\bullet$ & & & & \\
\hline Tietê/SP & $\bullet$ & & & \\
\hline Araraquara/SP & $\bullet$ & $\bullet$ & $\bullet$ & \\
\hline Barretos/SP & $\bullet$ & $\bullet$ & & \\
\hline Ipatinga/MG & $\bullet$ & $\bullet$ & & $\bullet$ \\
\hline Guarulhos/SP & $\bullet$ & $\bullet$ & $\bullet$ & \\
\hline São Vicente/SP & $\bullet$ & $\bullet$ & $\bullet$ & & $\bullet$ \\
\hline Goiânia/GO & $\bullet$ & $\bullet$ & $\bullet$ & \\
\hline Camboriú/SP & $\bullet$ & $\bullet$ & & \\
\hline Seropédica/RJ & $\bullet$ & $\bullet$ & & \\
\hline
\end{tabular}

Pela análise do quadro 4 percebe-se que nos municípios estudados não existe incentivo para qualidade ambiental interna nas construções, tais como iluminação, insolação mínima, conforto térmico, acústica, emissão de compostos orgânicos voláteis e gás. Pode-se verificar também que 6 (seis) municípios expandiram suas considerações em relação às construções sustentáveis, não se limitando apenas a incentivar as áreas verdes para permeabilidade do solo.

Como os incentivos concedidos pelas normas municipais são mais específicos do que os apresentados no quadro 4, procedeu-se a um desmembramento de parâmetros constantes na legislação, a saber: 
1. Espaço sustentável: foram encontrados parâmetros comuns, como permeabilidade, arborização, telhados verdes, horta e calçada ecológica. Cabe destacar que somente esses parâmetros não englobam todos os aspectos relacionados a espaços sustentáveis.

2. Materiais e recursos: materiais sustentáveis.

3. Energia e atmosfera: aquecimento solar hidráulico, energia solar e energia eólica.

4. Uso racional da água: captação de águas pluviais e reuso de água.

5. Outros: fatores externos (coleta seletiva).

Em termos práticos, os municípios concedem descontos no IPTU, usualmente em porcentagens, conforme tabela 1. Diante disso, buscou-se caracterizar a proporção de incentivo de cada município em relação a desconto no IPTU, bem como qual parâmetro de construção sustentável está sendo mais incentivado.

\section{Tabela 1 - Descontos percentuais no IPTU relativos a parâmetros específicos de} construções sustentáveis

\begin{tabular}{|c|c|c|c|c|c|c|c|c|c|c|c|c|c|}
\hline$\frac{\frac{o}{a}}{\frac{\mathrm{n}}{\mathrm{U}}}$ & 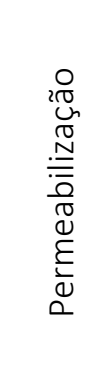 & $\begin{array}{l}\text { O } \\
2 \mathbb{0} \\
\text { Un } \\
\stackrel{N}{1} \\
\frac{1}{0} \\
\frac{0}{L} \\
\frac{1}{4}\end{array}$ & 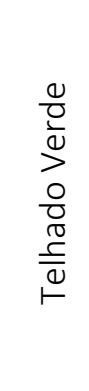 & 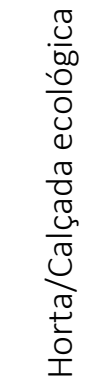 & 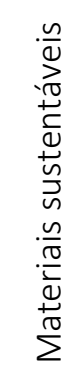 & 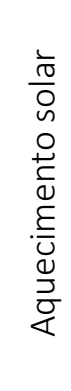 & 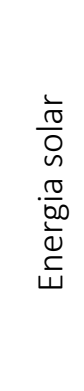 & 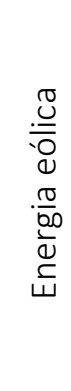 & 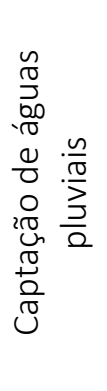 & 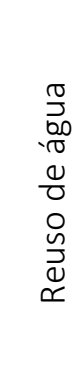 & 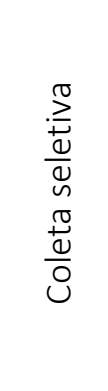 & $\begin{array}{l}\text { ○ } \\
\stackrel{2}{ \pm} \\
\stackrel{2}{\supset} \\
0\end{array}$ & 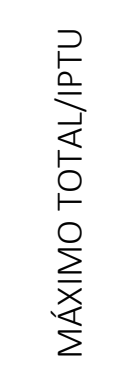 \\
\hline Americana/SP & $\begin{array}{l}10- \\
20 \%\end{array}$ & - & - & & - & - & - & - & - & - & - & - & $20 \%$ \\
\hline $\begin{array}{l}\text { Campos do } \\
\text { Jordão/SP }\end{array}$ & $\begin{array}{l}10- \\
50 \%\end{array}$ & - & - & & - & - & - & - & - & - & - & - & $50 \%$ \\
\hline Tietê/SP & $\begin{array}{c}40- \\
100 \%\end{array}$ & - & - & & - & - & - & - & - & - & - & - & $100 \%$ \\
\hline Araraquara/SP & $\begin{array}{l}10- \\
40 \%\end{array}$ & & & & & & & & & & & & $40 \%$ \\
\hline Barretos/SP & - & $10 \% *$ & & $10 \% *$ & & & & & & & $10 \% *$ & & $10 \% * *$ \\
\hline Ipatinga/MG & $5 \%$ & - & - & - & $5 \%$ & $5 \%$ & - & - & $3 \%$ & $3 \%$ & - & - & $21 \%$ \\
\hline Guarulhos/SP & - & - & $3 \%$ & - & $3 \%$ & $3 \%$ & $3 \%$ & $5 \%$ & $3 \%$ & $3 \%$ & $3 \%$ & $3 \%$ & $29 \%$ \\
\hline $\begin{array}{c}\text { São } \\
\text { Vicente/SP }\end{array}$ & $7 \%$ & $3 \%$ & $10 \%$ & $13 \%$ & $23 \%$ & $4 \%$ & $13 \%$ & - & - & $22 \%$ & $3 \%$ & $20 \%$ & $100 \%$ \\
\hline Goiânia/GO & $3 \%$ & $3 \%$ & $3 \%$ & $3 \%$ & $3 \%$ & $2 \%$ & $2 \%$ & $3 \%$ & - & - & $3 \%$ & - & $22 \%$ \\
\hline Camboriú/SP & - & - & - & - & $6 \%$ & $4 \%$ & - & - & $2 \%$ & $2 \%$ & - & - & $14 \%$ \\
\hline Seropédica/RJ & - & $4 \%$ & - & - & $3 \%$ & $4 \%$ & $3 \%$ & $3 \%$ & $3 \%$ & - & $2 \%$ & $6 \%$ & $15 \% * *$ \\
\hline
\end{tabular}

Fonte: elaborado pelas autoras. 
Da análise da Tabela 1 pode-se verificar que os municípios vêm dando mais ênfase nas questões de espaço sustentáveis e menos ênfase no que se refere à energia eólica e captação de águas pluviais, conforme demonstra a figura 2 .

Figura 2 - Percentual de tipos de incentivos

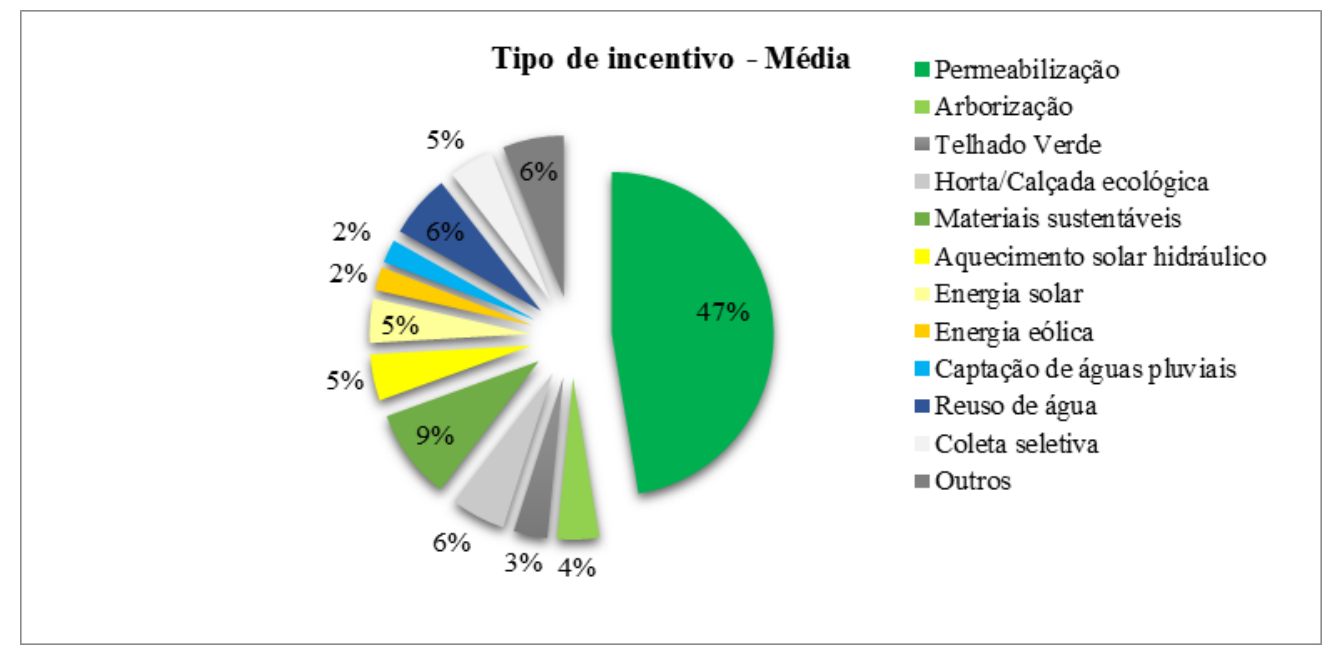

Fonte: elaborado pelas autoras

Observou-se que 60\% (sessenta por cento) dos incentivos recaem sobre o espaço ocupado e parte deles apresentava propostas limitada a inserção de áreas permeáveis ou de vegetação como parte integrante do imóvel, que podem ser enquadradas em "espaço sustentável". Contudo, não encerra todas as facetas de espaços sustentáveis que envolvem mobilidade, acessibilidade, redução de movimento de terra, etc. O tema vegetação, seja pelo incentivo às áreas permeáveis, seja por incentivo à arborização, hortas ou telhados verdes e calçadas ecológicas é mais frequente do que os demais aspectos que envolvem construções sustentáveis.

Sobre energia e atmosfera recaem 12\%: aquecimento e energia solar, seguido de eólica. Em materiais e recursos recaem 9\%: este parâmetro aparece com frequência nos incentivos fiscais municipais, entretanto, variando muito em percentuais de desconto no IPTU e em detalhamento construtivo. O uso racional da água soma $8 \%$ além de $11 \%$ de incentivos não vinculados diretamente aos projetos de construção sustentável.

Baseando-se nas porcentagens trazidas pela figura 2, o gráfico 1 mostra a porcentagem máxima que cada município concede de isenção no IPTU relacionado às construções sustentáveis. Nota-se que a variação percentual é bastante dispare. 
Gráfico 1 - Percentual de tipos de incentivos

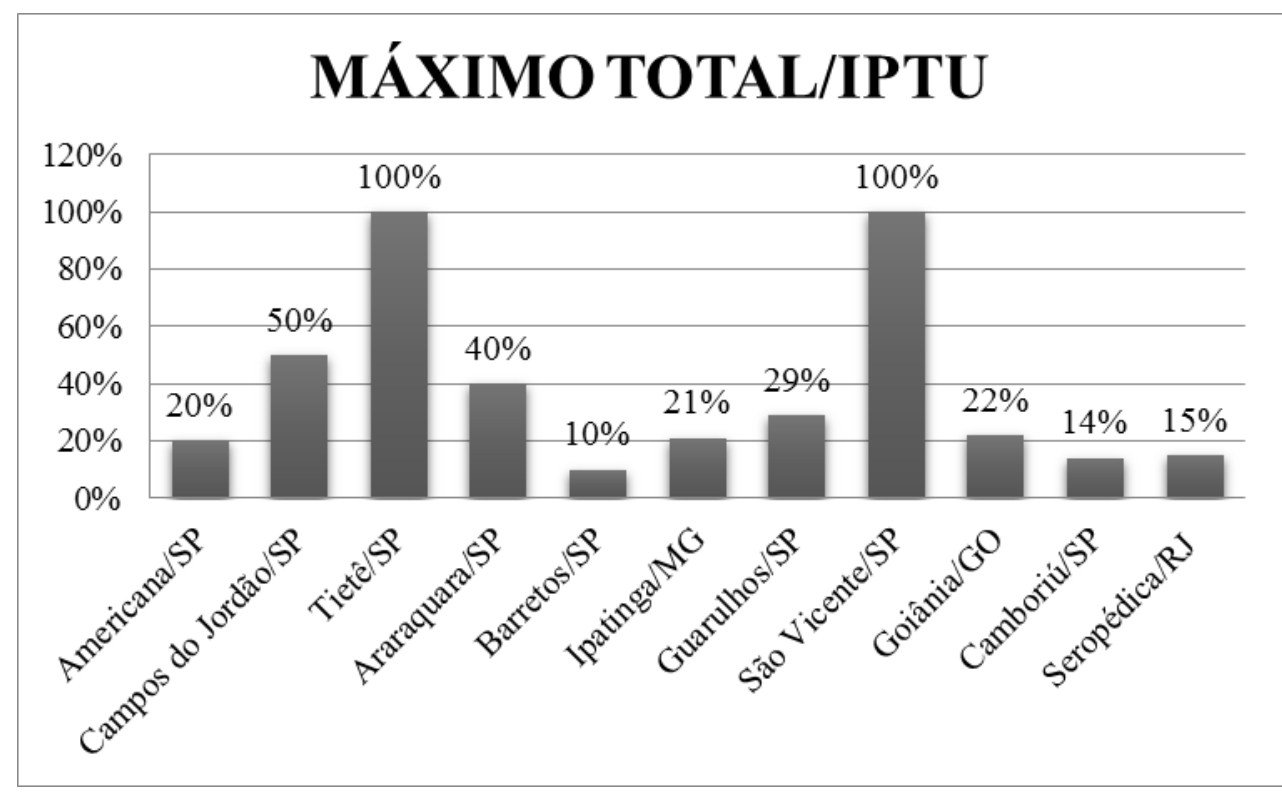

Fonte: elaborado pelas autoras

\section{CONSIDERAÇÕES FINAIS}

Ao menos em relação aos 11 (onze) municípios objetos do estudo, os altos custos que envolvem a adoção de medidas sustentáveis nas construções urbanas não são mais justificativa para não se optar por alternativas que preservem o meio ambiente, já que os gastos iniciais com as soluções são recuperados por meio da redução da alíquota do IPTU do imóvel.

No entanto, apesar dos significativos incentivos apresentados, a maioria dos municípios brasileiros ainda não possui nenhum incentivo legal à adoção de medidas de sustentabilidade nas construções empreendidas em seu território, o que tem dificultado o processo de mudança dos paradigmas tradicionais da construção civil em razão dos custos dos materiais e serviços envolvidos.

Constatou-se que em todos os casos, o incentivo legal é concedido em forma de desconto na alíquota do IPTU, sendo que o desconto pode chegar até a 100\% (cem por cento) do valor do imposto, caso o imóvel atenda a todos os parâmetros de sustentabilidade previstos na lei municipal.

Alguns parâmetros de sustentabilidade estão mais presentes do que outros nos incentivos legais à adoção de medidas sustentáveis nas construções urbanas, tais como iluminação natural, telhado verde, captação de água de chuva e sistema de aquecimento solar. Porém, existem outros parâmetros arquitetônicos de construções sustentáveis sendo utilizados por entidades 
certificadoras de edifícios verdes, como a GBCBRASIL, o que demonstra que outros padrões de sustentabilidade podem ser incentivados legalmente em projetos arquitetônicos que atenderão às necessidades da geração atual sem comprometer a capacidade de as gerações futuras poderem atender às suas próprias necessidades.

Entretanto, ressalva-se que o presente estudo se refere aos incentivos legalmente instituídos, mas isso não significa que não haja outras formas normativas que regulamentem critérios de sustentabilidade nas construções urbanas por todo o país. Porém, em sua grande maioria, essas regulamentações normativas estabelecem princípios e diretrizes que não atuam de forma impositiva e não trazem em seu bojo incentivos financeiros concretos para aqueles que irão arcar com os custos de uma construção que cause menos impacto no ambiente já desgastado dos grandes centros urbanos.

\section{REFERÊNCIAS BIBLIOGRÁFICAS}

AMERICANA (SP). Lei no 4.448, de 05 de janeiro de 2007. Autoriza o poder executivo a conceder redução do iptu a imóveis dotados de áreas verdes descobertas com solo permeável, na forma que especifica, e dá outras providências. Disponível em: < http://cmamericana.jusbrasil.com.br/legislacao/247147/lei-4448-07>. Acesso em: 22 fev. 2015.

ARARAQUARA (SP), Lei no 7.152, de 08 de dezembro de 2009. Concede isenção de imposto predial e territorial urbano para propriedades que conservarem área arborizada-IPTU VERDE. Disponível em: $<$ https://www.leismunicipais.com.br/a/sp/a/araraquara/lei-ordinaria/2009/715/7152/lei-ordinarian-7152-2009-concede-isencao-de-imposto-predial-e-territorial-urbano-para-propriedades-queconservarem-area-arborizada-iptu-verde.html>. Acesso em: 23 fev. 2015.

BARRETOS (SP). Lei Complementar no 122, de 18 de dezembro de 2009. Dispõe sobre o desconto de $10 \%$ (dez por cento) no imposto predial e territorial urbano-IPTU, ao contribuinte que fizer adesão ao programa "Município Verde". Disponível em: < https://www.leismunicipais.com.br/a/sp/b/barretos/lei-complementar/2009/12/122/leicomplementar-n-122-2009-dispoe-sobre-o-desconto-de-10-dez-por-cento-no-imposto-predial-eterritorial-urbano-iptu-ao-contribuinte-que-fizer-adesao-ao-programa-municipio-verde.html>. Acesso em: 23 fev. 2015.

BRASIL. Lei no 6.938, de 31 de agosto de 1981. Dispõe sobre a Política Nacional do Meio Ambiente, seus fins e mecanismos de formulação e aplicação, e dá outras providências. Diário Oficial da União, Brasília, 02 set. 1981. Disponível em: <http://www.planalto.gov.br/ccivil_03/leis/L6938.htm>. Acesso em 12 fev. 2015.

Constituição da República Federativa do Brasil de 1988. Disponível em: < http://www.planalto.gov.br/ccivil_03/constituicao/constituicaocompilado.htm>. Acesso em: 23 fev. 2015.

Lei no 10.257, de 10 de julho de 2001. Disponível em: <http://www.planalto.gov.br/ccivil_03/leis/leis_2001/l10257.htm>. Acesso em: 19 fev. 2015. 
BROWN, G.Z.; DEKAY, M. Sol, Vento e Luz - Estratégias Para Projeto de Arquitetura. 2. ed. Porto Alegre: Artmed, 2004.

CAMBORIÚ (SC). Lei no 2.544 de 03 de junho de 2013. Institui o programa de incentivo e desconto, denominado "IPTU Verde" no âmbito do município de Camboriú e dá outras providências. Disponível em: $\quad$ <https://www.leismunicipais.com.br/a/sc/c/camboriu/lei-ordinaria/2013/254/2544/leiordinaria-n-2544-2013-institui-o-programa-de-incentivo-e-desconto-denominado-iptu-verde-noambito-do-municipio-de-camboriu-e-da-outras-providencias.html>. Acesso em: 27 fev. 2015.

CAMPOS DO JORDÃO (SP). Lei no 3.157, de 12 de junho 2008. Dispõe sobre desconto no IPTU referente a imóveis com área verde preservada. Disponível em: < http://www.camposdojordao.sp.gov.br/portal/images/arquivos/boletimeletronico/2008/boletim_0 9-08.pdf>. Acesso em: 20 fev. 2015.

CONSELHO NACIONAL DO MEIO AMBIENTE. Resolução no 307, de 5 de julho de 2002. Estabelece diretrizes, critérios e procedimentos para a gestão dos resíduos da construção civil. Diário Oficial da União, Brasília, 17 jul. 2002.2 Disponível em: <http://www.mma.gov.br/port/conama/legiabre.cfm?codlegi=307>. Acesso em: 23 fev. 2015.

FERREIRA, Luiz Pinto. O meio ambiente, os Crimes e os Danos Ecológicos. Revista do Instituto dos Advogados de Pernambuco, v.1 n.2, 2000.

GBCBRASIL. Green Building Council Brasil. Construindo um future sustentável. Disponível em: <http://gbcbrasil.org.br/sobre-certificado.php>. Acesso em: mar. 2016.

GUARULHOS (SP). Lei № 6.793, de 28 de dezembro de 2010. Dispõe sobre o lançamento, arrecadação e fiscalização do Imposto Sobre a Propriedade Predial e Territorial Urbana - IPTU e dá outras providências. Disponível em: < http://leis.guarulhos.sp.gov.br/06_prefeitura/leis/leis_download/06793lei.pdf>. Acesso em: 25 fev. 2015.

GOIÂNIA (GO). Lei Complementar no 235, de 28 de dezembro de 2012. Institui o PROGRAMA IPTU VERDE no Município de Goiânia. Disponível em: < http://www.goiania.go.gov.br/Download/legislacao/diariooficial/2012/do_20121228_000005500.p df>. Acesso em: 26 fev. 2015.

IPATINGA (MG). Lei no 2.646, de 21 de dezembro de 2009. Cria o programa IPTU Verde e autoriza a concessão de desconto no imposto predial e territorial urbano-IPTU como incentivo ao uso de tecnologias ambientais sustentáveis. Disponível em: <https://www.leismunicipais.com.br/a/mg/i/ipatinga/lei-ordinaria/2009/264/2646/lei-ordinaria-n2646-2009-cria-o-programa-iptu-verde-e-autoriza-a-concessao-de-desconto-no-imposto-predial-eterritorial-urbano-iptu-como-incentivo-ao-uso-de-tecnologias-ambientais-sustentaveis.html>. Acesso em: 24 fev. 2015.

JAHNKE, Letícia Thomasi; WILLANI, Sheila Marione Uhlmann; ARAÚJO, Tiago Luiz Rigon de Araújo. O IPTU VERDE: práticas sustentáveis trazem benefícios financeiros à população. Revista Eletrônica do Curso de Direito - UFSM. Santa Maria, v.8, 2013. Disponível em: 
<http://cascavel.ufsm.br/revistas/ojs2.2.2/index.php/revistadireito/article/view/8341/5026\#.VPC7r PnF-y2>. Acesso em: 23 fev. 2015.

KEELER, M., BURKE, B. (2010). Fundamentos de Projetos de Edificações Sustentáveis. Porto Alegre: Bookman.

LAMBERTS, Roberto; DUTRA, Luciano; PEREIRA, Fernando O. R. Eficiência energética na arquitetura. Disponível em: <http://www.mme.gov.br/documents/10584/1985241/Livro\%20\%20Efici\%C3\%AAncia\%20Energ\%C3\%A9tica\%20na\%20Arquitetura.pdf>. Acesso em: jan. 2016.

LENGEN, Johan Van. Manual do arquiteto descalço. São Paulo: Editora Empório do Livro, 2008.

ROMERO, Marcelo de Andrade; REIS, Lineu Belico dos. Eficiência energética em edifícios. Barueri: Manole, 2012.

SANT'ANNA, Daniele Ornaghi. Qualidade ambiental interna e satisfação dos usuários de agências bancárias certificadas verdes e similares convencionais em São Paulo. 2015. Tese (Doutorado em Tecnologia da Arquitetura) - Faculdade de Arquitetura e Urbanismo, Universidade de São Paulo, São Paulo, 2015. Disponível em: <http://www.teses.usp.br/teses/disponiveis/16/16132/tde29102015-144050/>. Acesso em: 2016-06-06.

SÃO VICENTE (SP). Lei Complementar no 634, de 05 de novembro de 2010. Dispõe sobre a autorização para redução de alíquota de Imposto Predial e Territorial Urbano - IPTU aos proprietários de imóveis residenciais, não-residenciais e não-edificados que adotem medidas visando à preservação e recuperação do meio ambiente, estimulando sua proteção e dá outras providências. Disponível em: <http://www.saovicente.sp.gov.br/ambiental/pdf_12/04/634.pdf>. Acesso em: 25 fev. 2015.

SEROPÉDICA (RJ). Lei no 526, de 15 de julho de 2014. Dispõe sobre a criação do programa de incentivos ambientais intitulado "IPTU Verde". Disponível em: < https://www.leismunicipais.com.br/a/rj/s/seropedica/lei-ordinaria/2014/52/526/lei-ordinaria-n526-2014-dispoe-sobre-a-criacao-do-programa-de-incentivos-ambientais-entitulado-iptuverde.html>. Acesso em: 28 fev. 2015.

TIETÊ (SP). Lei no 3.087, de 28 de agosto de 2009. Autoriza o poder executivo a instituir o projeto de preservação ambiental no município de Tietê "IPTU VERDE", conceder redução do IPTU na forma que especifica e dá outras providências. Disponível em: < https://www.leismunicipais.com.br/a/sp/t/tiete/lei-ordinaria/2009/308/3087/lei-ordinaria-n-30872009-autoriza-o-poder-executivo-a-instituir-o-projeto-de-preservacao-ambiental-no-municipio-detiete-iptu-verde-conceder-reducao-do-iptu-na-forma-que-especifica-e-da-outrasprovidencias.html>. Acesso em: 23 fev. 2015.

VAHAN, Agopyan. JOHN, M. Vanderley. O desafio da sustentabilidade na construção civil. v.5. Jose Goldemberg, Coordenador. São Paulo: Blucher, 2011.

YUDELSON, J. Green building A to Z: Understanding the language of Green building. Canada: New Society Publishers, 2007. 
Revista de Direito da Cidade

vol. 08, nㅇ 4. ISSN 2317-7721

DOI: $10.12957 /$ rdc.2016.23578

Trabalho enviado em 29 de junho de 2016.

Aceito em 12 de setembro de 2016. 